University of Nebraska - Lincoln

DigitalCommons@University of Nebraska - Lincoln

Faculty Publications, Department of Psychology

Psychology, Department of

2009

\title{
Pavlovian drug discrimination with bupropion as a feature positive occasion setter: Substitution by methamphetamine and nicotine, but not cocaine
}

Jamie L. Wilkinson

University of Nebraska-Lincoln

Chia Li

University of Nebraska-Lincoln

Rick A. Bevins

University of Nebraska-Lincoln, rbevins1@unl.edu

Follow this and additional works at: http://digitalcommons.unl.edu/psychfacpub

Part of the Psychology Commons

Wilkinson, Jamie L.; Li, Chia; and Bevins, Rick A., "Pavlovian drug discrimination with bupropion as a feature positive occasion setter: Substitution by methamphetamine and nicotine, but not cocaine" (2009). Faculty Publications, Department of Psychology. 729.

http://digitalcommons.unl.edu/psychfacpub/729

This Article is brought to you for free and open access by the Psychology, Department of at DigitalCommons@University of Nebraska - Lincoln. It has been accepted for inclusion in Faculty Publications, Department of Psychology by an authorized administrator of DigitalCommons@University of Nebraska - Lincoln. 
Published in final edited form as:

Addict Biol. 2009 April ; 14(2): 165-173. doi:10.1111/j.1369-1600.2008.00141.x. (C) 2008 The Authors. Published by John Wiley.

\title{
Pavlovian drug discrimination with bupropion as a feature positive occasion setter: Substitution by methamphetamine and nicotine, but not cocaine
}

\author{
Jamie L. Wilkinson, Chia Li, and Rick A. Bevins \\ University of Nebraska-Lincoln
}

\begin{abstract}
Bupropion can serve as a discriminative stimulus $\left(\mathrm{S}^{\mathrm{D}}\right)$ in an operant drug discrimination task, and a variety of stimulants substitute for the bupropion $\mathrm{S}^{\mathrm{D}}$. There are no reports, however, of bupropion functioning as a Pavlovian occasion setter (i.e., feature positive modulator). The present experiment seeks to fill this gap in the literature by training bupropion in rats as a feature positive modulator that disambiguates when a light will be paired with sucrose. Specifically, on bupropion $(10 \mathrm{mg} / \mathrm{kg}$ IP) sessions, offset of 15 -sec cue lights were followed by brief delivery of liquid sucrose; saline sessions were similar except no sucrose was available. Rats readily acquired the discrimination with more conditioned responding to the light on bupropion sessions. Bupropion is approved for use as a smoking cessation aid, and more recently has drawn attention as a potential pharmacotherapy for cocaine and methamphetamine abuse. Accordingly, after discrimination training we tested the ability of cocaine ( 1 to $10 \mathrm{mg} / \mathrm{kg}$ ), methamphetamine $(0.1 \mathrm{to} 1 \mathrm{mg} / \mathrm{kg}$ ), and nicotine $(0.00625$ to $0.2 \mathrm{mg} / \mathrm{kg})$ to substitute for the bupropion feature. Nicotine $(0.05 \mathrm{mg} / \mathrm{kg})$ and methamphetamine $(0.3 \mathrm{mg} / \mathrm{kg})$ substituted fully for bupropion; cocaine did not substitute. These results extend previous research on shared stimulus properties between bupropion and other stimulants to a Pavlovian occasion setting function. Further, this is the first report of nicotine and methamphetamine substitution for bupropion. The overlap in stimulus properties might explain the effectiveness of bupropion as a smoking cessation aid and highlight the possible utility of bupropion for treatment of stimulant use disorder.
\end{abstract}

\section{Keywords}

Pavlovian conditioning; stimulant use disorder; Wellbutrin; Zyban

\section{Introduction}

\begin{abstract}
Substance use is a major health and economic concern worldwide. New treatment options are constantly being sought to help improve rates of cessation and prevent relapse. Pharmacotherapies are often used, in addition to behavioral or cognitive therapies, in drug dependence treatment programs. One example of a pharmacotherapy is the use of bupropion hydrochloride (WellbutrinR, ZybanR). Bupropion is prescribed for depression, smoking cessation, and attention deficit hyperactivity disorder (ADHD). Although the exact mechanism that makes bupropion effective as a smoking cessation aid is not clear, bupropion does share many behavioral and neurophysiological similarities with stimulants. For example, acute administration of bupropion in rodents produces dose-dependent
\end{abstract}

\footnotetext{
${ }^{\square}$ Address Correspondence to: Rick A. Bevins, Department of Psychology, University of Nebraska-Lincoln, Lincoln, NE 68588-0308, Phone: 402\472-1189, FAX: 402\472-4637, rbevins1@unl.edu.
} 
increases in locomotor activity (Cooper et al., 1980; Nomikos et al., 1992; Ortmann, 1985; Wilkinson et al., 2006; Wilkinson and Bevins, 2007) that is enhanced with repeated administration (Nomikos et al., 1992). Similar to other psychomotor stimulants, bupropion produces a conditioned place preference in rats (Ortmann, 1985) and is self-administered by both rats (Tella et al., 1997) and primates (Lamb and Griffiths, 1990). Bupropion also induces an increase in extracellular dopamine concentration in the nucleus accumbens shell (Nomikos et al., 1992), an effect shared with amphetamine, cocaine, and nicotine (Carboni et al., 1989; Nisell et al., 1997).

In addition to the rewarding and locomotor activating effects, bupropion has interoceptive stimulus properties. Knowledge about the neuropharmacological and behavioral properties of a drug is often gained by examining its interoceptive (subjective) effects. One popular method for assessing the subjective effects of a drug is the two-lever operant drug discrimination task. In this task, subjects (often rats) are reinforced for lever presses on the active (e.g., right) lever on drug session; opposite lever presses (e.g., left) are not reinforced. On saline sessions the reinforcement contingencies are switched. That is, left lever presses are reinforced and right lever presses are now under extinction. In this task, bupropion is said to function as a discriminative stimulus $\left(S^{D}\right)$. Several previous studies have shown that a range of doses of bupropion $\left(17-40 \mathrm{mg} / \mathrm{kg}\right.$ ) can serve as a $\mathrm{S}^{\mathrm{D}}$ (Blitzer and Becker, 1985; Jones et al., 1980; Terry and Katz, 1997). Further, the stimulants $d$-amphetamine, caffeine, cocaine, methylphenidate, and nomifensine produced full substitution with at least $80 \%$ bupropion-appropriate responding in generalization tests (Blitzer and Becker, 1985; Jones et al., 1980; Terry and Katz, 1997).

The interoceptive stimulus properties of a drug can also disambiguate the occurrence of a stimulus-stimulus association. That is, the subjective effects of the drug "sets the occasion" upon which a Pavlovian association will be in force. Previous research has demonstrated that $d$-amphetamine, caffeine, chlordiazepoxide, cocaine, methamphetamine, and nicotine can serve as occasion setters (Miller et al., 2002; Murray and Bevins, 2007a; Palmatier et al., 2004, 2005; Palmatier and Bevins, 2007; Parker et al., 1994; Reichel et al., 2007a; Troisi and Akins, 2004). In the research from our laboratory with rats, a brief (e.g., 15-sec) cue light illumination served as a conditioned stimulus (CS) and was followed by 4-sec access to sucrose in a dipper receptacle (unconditioned stimulus; US) on drug sessions. On saline sessions, the same cue light was presented but there was no scheduled outcome. Thus, the drug state sets the occasion upon which the light CS was paired with the sucrose US. Dipper entries [i.e., goal tracking; Farwell and Ayres (1979)] increased during the cue light only on drug sessions. This outcome was taken to indicate that the subjective effects of the drug functioned as positive occasion setter that modulated conditioned responding to the cue light through higher-order Pavlovian associations [see Palmatier and Bevins (2007) for a more detailed discussion]. There are no published reports of bupropion functioning as a positive occasion setter. Therefore, one goal of the present research was to test whether bupropion would serve as an occasion setter for an appetitive stimulus-stimulus association.

It is important to demonstrate that bupropion can serve as an occasion setter, because some individuals have hypothesized that bupropion is an effective smoking cessation aid due to its behavioral and physiological similarities with nicotine (e.g., Wiley et al., 2002; Rauhut et al., 2003; Shoaib et al., 2003; Wilkinson et al., 2006; see Dwoskin et al., 2006 for a review). These same characteristics have also prompted consideration of bupropion as a potential pharmacotherapy for other stimulant use disorders. In fact, some early preclinical and clinical research suggests that bupropion might be effective in treating cocaine and methamphetamine dependence (e.g., Elkashef et al., 2008; Levin et al., 2002, 2005; Newton et al., 2005, 2006; O'Brien et al., 2005; Reichel et al., 2008). With this in mind, along with the success of establishing bupropion as a positive feature, we tested the ability of three 
common addictive stimulants, nicotine, cocaine, and methamphetamine to substitute for the bupropion feature.

\section{Materials and Methods}

\section{Animals}

Eight male Sprague-Dawley rats from Harlan (Indianapolis, IN, USA) were housed separately in polycarbonate tubs lined with wood shavings in a temperature- and humiditycontrolled colony. Water was available continuously in the colony, but access to chow was restricted to maintain them at $85 \%$ of their free-feeding weights $(331 \pm 12 \mathrm{~g})$. This target weight was increased by $2 \mathrm{~g}$ approximately every 30 days. All experimental sessions were conducted during the light portion of a 12:12 hr light:dark cycle. Experimental protocols were approved by the University of Nebraska-Lincoln IACUC and followed the "Guide for the Care and Use of Laboratory Animals" (National Research Council, 1996).

\section{Apparatus}

Each of the eight conditioning chambers (ENV-008CT; Med Associates, Georgia, VT, USA) had clear polycarbonate ceiling, front wall, and back wall; sidewalls were aluminum. On the bottom center of one sidewall was a $5.2 \times 5.2 \mathrm{~cm}$ opening to a recessed dipper receptacle. Sucrose solution $(26 \% \mathrm{w} / \mathrm{v})$ was delivered via a $0.1-\mathrm{ml}$ cup attached to a dipper $\mathrm{arm}$. An infrared unit, located $1.2 \mathrm{~cm}$ within the receptacle and $3 \mathrm{~cm}$ from the floor, detected head entries. Mounted $6 \mathrm{~cm}$ above and to either side of the top edge of the dipper opening were two white cue lights $(28 \mathrm{~V}, 100 \mathrm{~mA})$. Illumination of the lights for $15 \mathrm{sec}$ served as the CS. Each chamber was housed in a sound-attenuating cubicle fitted with a fan to provide airflow and masking noise. During the testing phase of the preset experiment (see later), chambers were fitted with an infrared emitter/detector unit located on the front and back wall, $14.5 \mathrm{~cm}$ from each sidewall and $4 \mathrm{~cm}$ from the floor. Interruption of this infrared beam served as a measure of general activity (cf. Reichel et al., 2007a). A personal computer with Med-Associates interface and software controlled stimulus events and recorded dipper entries and chamber activity.

\section{Drugs}

Bupropion hydrochloride, cocaine hydrochloride, (-)nicotine hydrogen tartrate, and methamphetamine hydrochloride (Sigma, St. Louis, MO, USA) were dissolved in saline $(0.9 \% \mathrm{NaCl})$. The nicotine solution was brought to a $\mathrm{pH}$ of $7.0 \pm 0.2$ with a dilute $\mathrm{NaOH}$ solution and was administered via subcutaneous (SC) injection at a volume of $1 \mathrm{ml} / \mathrm{kg}$. All other compounds were injected intraperitoneally (IP) at the same volume. Nicotine doses were expressed as the base form; all other drug doses were expressed as the salt form. Injection routes, as well as injection-to-testing intervals and doses (see later) were adopted based on past subjective effect's research from our laboratory (Besheer et al., 2004; Wilkinson et al., 2006; Reichel et al., 2007a).

\section{Procedures}

\section{Acquisition}

Rats received bupropion $(10 \mathrm{mg} / \mathrm{kg}$ ) or saline injection IP $5 \mathrm{~min}$ before placement into the chamber. On bupropion sessions, the offset of each of the eight 15-sec light CS presentations was followed by $4-\mathrm{sec}$ access to sucrose. Saline sessions were similar except CS offset was followed by a 4-sec 'empty interval' (i.e., no sucrose). Each session lasted about 20 min. Acquisition consisted of 8-day cycles, each including 4 bupropion and 4 saline sessions. Session order for each rat was randomly determined with no more than 2 of a session type (i.e., bupropion or saline) occurring consecutively in a cycle. The time before 
onset of the first CS varied from 90 to $180 \mathrm{sec}$ (mean=135 sec) with time between sucrose offset (or empty interval) and the next CS onset varying from 75 to $165 \mathrm{sec}$ (mean=120 sec). Rats received 16 bupropion and 16 saline sessions before the testing began.

\section{Bupropion and Nicotine Substitution Tests}

For testing, cycles were shifted from 8 to 5 days; each cycle included 2 bupropion and 2 saline training sessions followed by a test session. Training sessions were identical to those in acquisition. Data from these sessions were used to determine whether a rat met performance criteria for testing (see later). On test days, rats were injected with bupropion $(1.25,2.5,5,10,20,30 \mathrm{mg} / \mathrm{kg} \mathrm{IP})$, nicotine $(0.00625,0.0125,0.025,0.05,0.1,0.2 \mathrm{mg} / \mathrm{kg}$ $\mathrm{SC}$ ) or saline (IP) $5 \mathrm{~min}$ before placement. Each rat was assigned a random order of the test solutions. During each 4-min test session rats received a single presentation of the 15 -sec light CS; sucrose was withheld on test days. The time between the start of the test session and onset of the CS varied as in the acquisition phase. Rats that did not meet criteria remained in the home cage on the test day.

\section{Cocaine and Methamphetamine Substitution Tests}

Upon completion of the bupropion generalization tests and the nicotine substitution tests, rats were tested with a random order of cocaine $(0.3,1,3,5,10 \mathrm{mg} / \mathrm{kg} \mathrm{IP})$, methamphetamine $(0.05,0.1,0.3,0.5,1 \mathrm{mg} / \mathrm{kg}$ IP), bupropion (10 mg/kg IP), or saline (IP). These substitution tests were similar to the previous tests. Cocaine and methamphetamine were injected $15 \mathrm{~min}$ before placement; bupropion and saline were injected $5 \mathrm{~min}$ before placement (cf. training sessions). One rat was removed from this phase because the discrimination was not maintained.

\section{Dependent measures and discrimination criteria}

The primary measure of conditioning was an elevation score. The elevation score was defined as the number of dipper entries during the 15-sec light CS minus the entries in the 15 -sec interval immediately before CS onset (pre-CS period). The elevation score controls for individual differences in baseline levels of dipper entries and allows comparison with previously published research from our laboratory on Pavlovian drug features (Bevins et al., 2006; Palmatier et al., 2004, 2005; Murray and Bevins, 2007a; Reichel et al., 2007a). As noted earlier, we fitted the chambers with an emitter/detector unit partway through the experiment. Thus, we were able to examine chamber activity during the cocaine and methamphetamine substitution test phase. To be tested a rat was required to have 1) a mean elevation score on each of the previous two positive sessions (i.e., bupropion) $\geq 3$ higher than the mean elevation score on the each of the previous two negative sessions (i.e., saline) and 2) the first elevation score on the last positive session had to be greater than the first elevation score on the last negative session (cf. Bevins et al., 2006; Palmatier et al., 2004, 2005; Murray and Bevins, 2007a; Reichel et al., 2007a).

\section{Data analyses}

Acquisition data were analyzed using a two-way repeated measures analysis of variance (ANOVA) with drug (bupropion versus saline) and session (1 to 16) as the two factors. Oneway ANOVAs were used to examine dipper entries and chamber activity during substitution tests. Post-hoc comparisons prompted by a significant F-value used Fishers least significant difference minimum mean difference $\left(\mathrm{LSD}_{\mathrm{mmd}}\right)$ follow-up tests. These comparisons were limited to contrasting each test value to a saline value; doses that produced elevated responding relative to saline were then compared to the $10 \mathrm{mg} / \mathrm{kg}$ training dose of bupropion. Further, a paired t-test was used to confirm that light-evoked responding and 
locomotor activity on the bupropion test was higher than saline test during the cocaine and methamphetamine substitution phase. Full substitution was defined as conditioned responding above saline and not different from the training dose of bupropion. Partial substitution was declared when responding was above saline but remained below the bupropion training dose. For statistical significance, we used a two-tailed rejection region of 0.05 for all tests. For drugs that produced full substitution, the median effective dose $\left(\mathrm{ED}_{50}\right)$ was calculated using linear regression on the ascending limb of the dose-effect function.

\section{Results}

\section{Acquisition}

One of the eight rats never acquired a stable discrimination as defined by testing criteria and did not contribute to any of the subsequent testing phases. Thus, analysis was conducted with data from seven rats; removal of this one rat did not change the acquisition results. For the mean session elevation score, there was a main effect of Drug, $F(1,6)=23.35, p=0.003$, and Session, $\mathrm{F}(15,90)=9.13, \mathrm{p}<0.001$. The Drug $\times$ Session Interaction was also significant, $\mathrm{F}(15,90)=7.67, \mathrm{p}<0.001$, indicating increased conditioned responding to the light on later bupropion sessions (see Figure 1A). Post-hoc comparisons $\left(\mathrm{LSD}_{\mathrm{mmd}}=1.36\right)$ revealed that elevation scores were significantly different on sessions $7-16$. We also examined elevation scores to the first presentation of the CS across the acquisition sessions (see Figure 1B). This measure of conditioning is less susceptible to influences of sucrose access on conditioned responding (see later Discussion). The main effect of Drug was not significant, $F(1,6)=3.53$, $\mathrm{p}=0.11$. There was a main effect of Session, $\mathrm{F}(15,90)=4.70$, $\mathrm{p}<0.001$, and a Drug $\times$ Session interaction, $\mathrm{F}(15,90)=2.70, \mathrm{p}=0.002$. Post-hoc comparisons $\left(\mathrm{LSD}_{\mathrm{mmd}}=2.99\right)$ showed that the first elevation scores on bupropion were higher on sessions 12 and 14-16.

\section{Bupropion and Nicotine Substitution Tests}

Conditioned responding modulated by the bupropion feature appeared dose dependent (Figure 2). A one-way ANOVA examining elevation scores for bupropion substitution revealed a main effect of Dose, $F(5,30)=2.45, p=0.04$. Follow-up analyses indicated that 10 and $20 \mathrm{mg} / \mathrm{kg}$ bupropion produced responding above saline levels $\left(\mathrm{LSD}_{\mathrm{mmd}}=4.1\right)$.

Responding evoked by $20 \mathrm{mg} / \mathrm{kg}$ bupropion was similar to responding at the $10 \mathrm{mg} / \mathrm{kg}$ training dose indicating comparable stimulus effects. The $\mathrm{ED}_{50}$ for bupropion generalization was $4.75 \mathrm{mg} / \mathrm{kg}$. Nicotine substituted for the bupropion feature in a dose-dependent manner as denoted by the significant one-way ANOVA, $\mathrm{F}(5,30)=2.92$, $\mathrm{p}=0.02$. Conditioned responding was elevated above saline at $0.05 \mathrm{mg} / \mathrm{kg}$ nicotine $\left(\mathrm{LSD}_{\mathrm{mmd}}=2.5\right)$; responding at this dose was not different from $10 \mathrm{mg} / \mathrm{kg}$ bupropion suggesting full substitution by this low dose of nicotine $\left(\mathrm{ED}_{50}=0.022 \mathrm{mg} / \mathrm{kg}\right)$.

\section{Cocaine and Methamphetamine Substitution Testing}

A paired t-test confirmed that conditioned responding to the light on the $10 \mathrm{mg} / \mathrm{kg}$ bupropion test session was elevated compared to saline, $t(5)=5.3, p=0.003$ (Figure 3A). For cocaine the ANOVA was not significant, $\mathrm{F}<1$, indicating that cocaine did not substitute for bupropion feature. In contrast, the ANOVA was significant, $F(4,20)=3.31, p=0.03$, when methamphetamine was the substitution drug. Follow-up analyses revealed that conditioned responding was elevated for 0.1 and $0.3 \mathrm{mg} / \mathrm{kg}$ methamphetamine compared to saline $\left(\mathrm{LSD}_{\mathrm{mmd}}=2.6\right.$ ). Responding at $0.1 \mathrm{mg} / \mathrm{kg}$ methamphetamine was less than $10 \mathrm{mg} / \mathrm{kg}$ bupropion indicating partial substitution, but conditioned responding at $0.3 \mathrm{mg} / \mathrm{kg}$ methamphetamine was similar to bupropion indicating full substitution at this dose. This data pattern indicates that methamphetamine dose dependently substituted for bupropion $\left(\mathrm{ED}_{50}=0.19 \mathrm{mg} / \mathrm{kg}\right)$. 
In addition to the elevation scores, we also recorded general chamber activity during this phase (see Figure 3B). A pairwise t-test showed that bupropion increased activity compared to saline, $\mathrm{t}(5)=-3.57, \mathrm{p}=0.016$. The ANOVA was significant for cocaine, $\mathrm{F}(4,20)=5.69$, $\mathrm{p}<0.001$. Cocaine $(3,5$, and $10 \mathrm{mg} / \mathrm{kg})$ increased activity compared to saline $\left(\mathrm{LSD}_{\mathrm{mmd}}=23.3\right)$; the increase in activity was similar to bupropion-induced activity. This activity pattern, in combination with the lack of substitution by cocaine, suggests a dissociation between the pattern of substitution and the drug psychomotor effects. The ANOVA for general chamber activity for methamphetamine was also significant, $\mathrm{F}(4,20)=4.18, \mathrm{p}=0.013$. Post-hoc comparisons $\left(\mathrm{LSD}_{\mathrm{mmd}}=18.4\right)$ revealed that 0.1 to $1 \mathrm{mg} / \mathrm{kg}$ produced increased activity compared to saline; this increase was comparable to bupropion.

\section{Discussion}

Most of the literature investigating the subjective effects of bupropion has examined the ability of bupropion to substitute for other training drugs. For example, previous studies have reported the ability of bupropion to substitute for the interoceptive stimulus effects of nicotine in both operant conditioning tasks (Desai et al., 2003; Wiley et al., 2002; Young and Glennon, 2002 but see Shoaib et al., 2003) and in Pavlovian conditioning tasks (Besheer et al., 2004; Bevins et al., 2006; Reichel et al., 2007b). Additionally, several previous studies have shown that bupropion substitutes for the subjective effects of cocaine in rats (Broadbent et al., 1995; Katz et al., 2000; Lamb and Griffith, 1990; Quinton et al., 2006), monkeys (Kleven et al., 1990; Spealman et al., 1990), and pigeons (Johanson et al., 1993). Further, bupropion substitutes for methamphetamine $S^{\mathrm{D}}$ (Munzar and Goldberg, 2000; Sasaki et al., 1995) or Pavlovian occasion setter (Reichel et al., 2007a). Notably, the literature examining the ability of other drugs to substitute for the subjective effects of bupropion when it is the training drug is more limited. To our knowledge, there are only 3 published reports of bupropion serving as the training drug in a discrimination task; all of these studies used a two manipulanda operant conditioning paradigm. A variety of classic stimulants such as $d$-amphetamine, caffeine, cocaine, and methylphenidate substitute for a bupropion $S^{\mathrm{D}}$ (Blitzer and Becker, 1985; Jones et al., 1980; Terry and Katz, 1997). Unlike the present experiment, these studies did not examine whether nicotine or methamphetamine substituted for the subjective effects of bupropion.

Bupropion served as a feature positive occasion setter in the present study. This finding extends previous research that has shown bupropion can serve as a $S^{\mathrm{D}}$ in an operant drugdiscrimination task (Blitzer and Becker, 1985; Jones et al., 1980; Terry and Katz, 1997) to include a Pavlovian discrimination task. Previous studies that investigated the discriminative stimulus properties of bupropion have used training doses ranging from $10-40 \mathrm{mg} / \mathrm{kg}$ (Blitzer and Becker, 1985; Jones et al., 1980; Terry and Katz, 1997). Only the Jones et al. (1980) work used the lowest dose in this range as the training drug state; that is, the same dose we used as a positive drug feature. Although the bupropion/saline discrimination in the Jones et al. study was acquired within 60 training sessions, the discrimination was not sufficiently maintained for substitution testing. This was not the case in the present study. Most rats maintained the discrimination for over 200 training sessions. Further, conditioned responding to the light CS was sensitive to the dose of bupropion during test sessions. Responding decreased as the dose of bupropion was increased or decreased from the training dose. As one might anticipate by the lower training dose used in the present study, the $\mathrm{ED}_{50}$ of $4.75 \mathrm{mg} / \mathrm{kg}$ was lower than those reported $(6.74-18 \mathrm{mg} / \mathrm{kg})$ in previous studies using higher training doses of bupropion as the $\mathrm{S}^{\mathrm{D}}$ (Blitzer and Becker, 1985; Jones et al., 1980; Terry and Katz, 1997); as noted earlier Jones et al. (1980) could not generate a generalization curve from which to calculate an $\mathrm{ED}_{50}$ using $10 \mathrm{mg} / \mathrm{kg}$ bupropion. 
In the present study, nicotine $\left(\mathrm{ED}_{50}=0.022 \mathrm{mg} / \mathrm{kg}\right)$ and methamphetamine $\left(\mathrm{ED}_{50}=0.19 \mathrm{mg} /\right.$ $\mathrm{kg}$ ) produced dose-dependent substitution for the bupropion cue. To our knowledge, this is the first report of nicotine or methamphetamine substitution for any bupropion stimulus. The nicotine substitution pattern further supports the hypothesis that the efficacy of bupropion as a smoking cessation aid might reflect an overlap in underlying neurophysiological processes with nicotine (e.g., Wiley et al., 2002; Rauhut et al., 2003; Shoaib et al., 2003; Wilkinson et al., 2006, see Dwoskin et al., 2006 for a review). Additionally, the ability of methamphetamine to substitute for bupropion indicates shared subjective qualities. This finding was somewhat anticipated given that the drugs have similar behavioral profiles, both drugs have dopaminergic properties (Abekawa et al., 1994; Nomikos et al., 1992), and bupropion substitutes for a methamphetamine $S^{\mathrm{D}}$ (Munzar and Goldberg, 2000). These results support the suggestion that bupropion might be an effective pharmacological treatment for methamphetamine use (cf. Elkashef et al., 2008; Reichel et al., 2008).

Cocaine did not substitute for the bupropion occasion setter. This finding was somewhat surprising given that previous studies have consistently found that cocaine substitutes for a bupropion $\mathrm{S}^{\mathrm{D}}$ (Blitzer and Becker, 1985; Jones et al., 1980; Terry and Katz, 1997). Important procedural differences might explain the differences in results. Notably, all of the previous studies have been operant drug discrimination procedures that have trained bupropion as the $\mathrm{S}^{\mathrm{D}}$, whereas bupropion served as a positive feature (occasion setter) in the present study. Operant drug discrimination and Pavlovian drug feature tasks might tap into different subjective processes. Although this hypothesis is interesting and suggests a new set of intriguing research questions (see Murray \& Bevins, 2007b), our laboratory has not fully investigated this possible dissociation and acceptance of such a conclusion is premature.

Alternatively, the present study used a lower training dose of bupropion $(10 \mathrm{mg} / \mathrm{kg})$ than the previous reports that were able to conduct substitution tests $(17-40 \mathrm{mg} / \mathrm{kg}$; Blitzer and Becker, 1985; Jones et al., 1980; Terry and Katz, 1997). The interoceptive stimulus effects of bupropion might differ at high and low doses. Supporting this suggestion, results from the generalization function in the present study (see Figure 2) indicate that higher doses of bupropion $(30 \mathrm{mg} / \mathrm{kg}$ ) are subjectively different from $10 \mathrm{mg} / \mathrm{kg}$. That is, responding to the cue light was lower when rats were tested with $30 \mathrm{mg} / \mathrm{kg}$ bupropion compared to the training dose of $10 \mathrm{mg} / \mathrm{kg}$ bupropion. This difference in the subjective effects of the 10 versus 30 $\mathrm{mg} / \mathrm{kg}$ bupropion dose likely reflects differences in action across monoamine neurotransmitter systems (for reviews see Ascher et al., 1995; Dwoskin et al., 2006). Perhaps this difference also accounts for why cocaine did not substitute for the low dose of bupropion used in the present study. There is little within study parametric research on different treatment regimens with bupropion. However, across study comparisons would lead us to expect that the neurobiological effects and the long-term neuroadaptations will differ with bupropion dose and exposure pattern (cf. Ascher et al., 1995; Cooper et al., 1994; Dong and Blier, 2001; Ferris et al., 1983; Mansari et al., 2008). Keeping this point in mind, drugs can be conceptualized as complex compound (multimodal) stimuli composed of many stimulus elements; these elements correspond to the perceptible neurobiological action of drug (Balster, 1988). A logical extension of this analysis is that the interoceptive stimulus effects of a drug will vary according to treatment protocol if these protocols differentially alter relevant neurobiological processes. The present study did not directly compare the interoceptive stimulus effects of a low versus high dose of bupropion, but the difference between the present study and those that trained higher bupropion doses as a $S^{D}$ suggest the need for studies directly comparing their subjective effects.

To explain the lack of cocaine substitution in the present study other investigators have suggested that cocaine might elicit a different conditioned response (CR). Specifically, rats administered cocaine might be more prone to approach the light CS (i.e., sign track) than to 
approach the site of the US delivery (i.e., goal track). Although rats are sign tracking during positive occasion setting sessions (unpublished observations), our enthusiasm for this alternate CR explanation is dampened by two pieces of evidence from our laboratory. First, when methamphetamine $(0.5 \mathrm{mg} / \mathrm{kg}$, IP) was trained as a positive drug feature using goal tracking as the dependent measure, cocaine ( 1 to $5 \mathrm{mg} / \mathrm{kg}$ ) partially substituted for methamphetamine (Figure 3 of Reichel et al., 2007a). Second, in an unpublished study from our laboratory we trained cocaine $(5 \mathrm{mg} / \mathrm{kg}$, IP) as a positive drug feature in rats $(\mathrm{n}=14)$ using the exact same training protocol as the present study. After 16 cocaine and 16 saline sessions, rats acquired the Pavlovian discrimination. The mean rate of dipper entries (i.e., goal tracking) to the first light CS presentation in the last three cocaine session was $5.48( \pm$ $0.55)$; the rate during saline sessions was $1.62( \pm 0.32)$. Thus, whether cocaine was the training drug or the substitution drug, a goal-tracking CR was expressed above control levels. These two findings are clearly counter to the alternate CR account.

For the final substitution testing phase of the present study we added an infrared beam to the chamber as a way of measuring chamber activity. Cocaine and methamphetamine produced elevated general chamber activity compared to saline. This increase was expected given that both drugs are classic locomotor stimulants (e.g., Fontana, et al., 1993; Peterson \& Bevins, 2004). Interestingly, the increase in activity induced by these stimulants was similar to the increase observed with the $10 \mathrm{mg} / \mathrm{kg}$ training dose of bupropion. Previous studies have also demonstrated that bupropion is a locomotor stimulant (Cooper et al., 1980; Nomikos et al., 1992; Ortmann, 1985; Wilkinson et al., 2006; Wilkinson and Bevins, 2007). It is important to note the dissociation between increased chamber activity and substitution for the bupropion positive feature. Cocaine $(3,5$, and $10 \mathrm{mg} / \mathrm{kg}$ ) produced an increase in general chamber activity, but did not substitute for bupropion. Further, methamphetamine produced elevated general chamber activity at all but the lowest dose tested, yet only the $0.3 \mathrm{mg} / \mathrm{kg}$ dose produced light CS evoked conditioned responding comparable to bupropion. Taken together, these results suggest that the pattern of substitution for the bupropion feature was not simply a result of the locomotor activating effects of these drugs. That is, substitution appears to reflect the interoceptive stimulus effects of the drug and not merely its locomotor stimulant properties.

The present study fills a gap in the previous literature by demonstrating that bupropion can serve as a feature positive occasion setter. Given the importance of associative learning in theories of substance abuse (e.g., Anagnostaras and Robinson, 1995; Bevins and Palmatier, 2004; O'Brien et al., 1992; Siegel and Ramos, 2002), as well as the ability of drugs of abuse to function as occasion setters (e.g., Palmatier et al., 2005; Reichel et al., 2007a; Troisi and Akins, 2004), it is likely that the ability of bupropion to also server as a feature positive occasion setter will be of relevance to treatment approaches and its efficacy as a pharmacotherapy (see Bevins \& Palmatier, 2004; Bevins, in press). For instance, a positive drug feature trained in the same manner as the present report is impervious to extinction. That is, repeated presentation of the drug feature alone (no US or CS) has no effect on its later ability to facilitate responding (Palmatier and Bevins, 2007). This means that drug states could maintain their ability to modulate appetitive behavior related to rewards experienced during drug use even if the drug is later experienced in the absence of the reward and its associated stimuli. To alter the drug's ability to modulate conditioned responding, a counter conditioning history has to be provided (Miller \& Oberling, 1998). With drugs like methamphetamine, substitute drugs will be needed to provide such a conditioning history.

To our knowledge the present report provides the first demonstration of nicotine and methamphetamine substitution for the subjective effects of bupropion. Understanding the overlapping subjective effects of bupropion with nicotine, methamphetamine, and cocaine is 
important considering the current use of bupropion as a smoking cessation aid and the interest in bupropion as a treatment for stimulant use disorders (SUDs; see previous paragraph). The overlap in stimulus properties, demonstrated by substitution in Pavlovian and operant procedures, might explain the effectiveness of bupropion as a smoking cessation aid and highlight the possible utility of bupropion for treatment of SUDs especially methamphetamine (e.g., Levin et al., 2002; Newton et al., 2005, 2006; O'Brien et al., 2005; Reichel et al., 2008). Considering the lack of current effective pharmacological treatment for stimulant addiction, future research needs to further examine the potential of bupropion as a treatment for SUDs. A recent study by Elkashef and colleagues (2008) provides promise for the potential efficacy of bupropion as a treatment of methamphetamine dependence. This clinical study reports that, for individuals with low-to-moderate methamphetamine use, bupropion increased the number of drug free weeks during treatment compared to placebo (Elkashef et al., 2008).

\section{Acknowledgments}

We thank Jessica Linkugel, Carmela Reichel, and Amanda Struthers for their thoughtful comments on an earlier version of this report. The research and R. A. Bevins were supported by United States Public Health Service grant DA018114. J. L. Wilkinson was supported by Nebraska Tobacco Settlement Biomedical Research Enhancement Funds while preparing this manuscript for publication. All MED-PC programs used in the present article are available upon request.

\section{References}

Abekawa T, Ohmori T, Koyama T. Effects of repeated administration of a high dose of methamphetamine on dopamine and glutamate release in rat striatum and nucleus accumbens. Brain Research 1994;643:276-81. [PubMed: 7518327]

Anagnostaras SG, Robinson TE. Sensitization to the psychomotor stimulant effects of amphetamine: modulation by associative learning. Behavioral Neuroscience 1996;110:1397-1414. [PubMed: 8986341]

Ascher JA, Cole JO, Colin JN, Feighner JP, Ferris RM, Fibiger HC, et al. Bupropion: a review of its mechanism of antidepressant activity. Journal of Clinical Psychiatry 1995;56:395-401. [PubMed: 7665537]

Balster, RL. Drugs as chemical stimuli. In: Colpaert, FC.; Balster, RL., editors. Psychopharmacology Series 4: Transduction Mechanisms of Drug Stimuli. Springer; New York: 1988. p. 3-11.

Besheer J, Palmatier MI, Metschke DM, Bevins RA. Nicotine as a signal for the presence or absence of sucrose reward: a Pavlovian drug appetitive conditioningpreparation in rats. Psychopharmacology 2004;172:108-117. [PubMed: 14530902]

Bevins, RA. In: Bevins, RA.; Caggiula, AR., editors. Altering the motivational function of nicotine through conditioning processes; The Motivational Impact of Nicotine and its Role in Tobacco Use: The 55th Nebraska Symposium on Motivation; New York: Springer; in press

Bevins RA, Palmatier MI. Extending the role of associative learning processes in nicotine addiction. Behavioral and Cognitive Neuroscience Reviews 2004;3:143-158. [PubMed: 15653812]

Bevins RA, Peterson JL. Individual differences in rats' reactivity to novelty and the unconditioned and conditioned locomotor effects of methamphetamine. Pharmacol Biochem Behav 2004;79:65-74. [PubMed: 15388285]

Bevins RA, Wilkinson JL, Palmatier MI, Siebert HL, Wiltgen SM. Characterization of nicotine's ability to serve as a negative feature in a Pavlovian appetitive conditioning task in rats. Psychopharmacology 2006;184:470-81. [PubMed: 16047193]

Blitzer RD, Becker EB. Characterization of the bupropion cue in the rat: Lack of evidence for a dopaminergic mechanism. Psychopharmacology 1985;85:173-177. [PubMed: 2861618]

Broadbent J, Gaspard TM, Dworkin SI. Assessment of the discriminative stimulus effects of cocaine in the rat: lack of interaction with opioids. Pharmacol Biochem Behav 1995;51:379-85. [PubMed: 7667357] 
Carboni E, Imperato A, Perezzani L, Di Chiara G. Amphetamine, cocaine, phencyclidine and nomifensine increase extracellular dopamine concentrations preferentially in the nucleus accumbens of freely moving rats. Neuroscience 1989;28:653-661. [PubMed: 2710338]

Cooper BR, Hester TJ, Maxwell RA. Behavioral and biochemical effects of the antidepressant bupropion (Welbutrin): Evidence for selective blockade of dopamine uptake in vivo. J Pharmacol Exp Ther 1980;215:127-134. [PubMed: 6778989]

Cooper BR, Wang CM, Cox RF, Norton R, Shea V, Ferris RM. Evidence that the acute behavioral and electrophysiological effects of bupropion (Wellbutrin) are mediated by a noradrenergic mechanism. Neuropsychopharmacology 1994;11:133-141. [PubMed: 7840865]

Desai RI, Barber DJ, Terry P. Dopaminergic and cholinergic involvement in the discriminative stimulus effects of nicotine and cocaine in rats. Psychopharmacology 2003;167:335-343. [PubMed: 12684733]

Dong J, Blier P. Modification of norepinephrine and serotonin, but not dopamine by sustained bupropion treatment. Psychopharmacology 2001;155:52-57. [PubMed: 11374336]

Dwoskin LP, Rauhut AS, King-Pospisil KA, Bardo MT. Review of the pharmacology and clinical profile of bupropion, an antidepressant and tobacco use cessation agent. CNS Drug Reviews 2006;12:178-207. [PubMed: 17227286]

Elkashef AM, Rawson RA, Anderson AL, Li SH, Holmes T, Smith EV, Chiang N, Kahn R, Vocci F, Ling W, Pearce VJ, McCann M, Campbell J, Gorodetzky C, Haning W, Carlton B, Mawhinney J, Weis D. Bupropion for the treatment of methamphetamine dependence. Neuropsychopharmacology 2008;33:1162-70. [PubMed: 17581531]

Farwell BJ, Ayres JB. Stimulus-reinforcer and response-reinforcer relations in the control of conditioned appetitive headpoking ("goal tracking") in rats. Learning and Motivation 1979;10:295-312.

Ferris RM, Cooper BR, Maxwell RA. Studies of bupropion's mechanism of antidepressant activity. Journal of Clinical Psychiatry 1983;44:74-78. [PubMed: 6406468]

Fontana D, Post R, Weiss S, Pert A. The role of D1 and D2 dopamine receptors in the acquisition and expression of cocaine-induced conditioned increases in locomotor behavior. Behav Pharmacol 1993;4:375-387. [PubMed: 11224206]

Johanson CE, Barrett JE. The discriminative stimulus effects of cocaine in pigeons. J Pharmacol Exp Ther 1993;267:1-8. [PubMed: 8229735]

Jones CN, Howard JL, McBennett ST. Stimulus properties of antidepressants in the rat. Psychopharmacology 1980;67:111-118. [PubMed: 6768086]

Katz JL, Izenwasser S, Terry P. Relationships among dopamine transporter affinities and cocaine-like discriminative-stimulus effects. Psychopharmacology 2000;148:90-98. [PubMed: 10663422]

Kleven MS, Anthony EW, Woolverton WL. Pharmacological characterization of the discriminative stimulus effects of cocaine in rhesus monkeys. J Pharmacol Exp Ther 1990;254:312-317. [PubMed: 2195158]

Lamb RJ, Griffiths RR. Self-administration in baboons and the discriminative stimulus effects in rats of bupropion, nomifensine, diclofensine and imipramine. Psychopharmacology 1990;102:183-90. [PubMed: 2125734]

Levin FR, Evans SM, McDowell DM. Bupropion treatment for cocaine abuse and adult attentiondeficit/hyperactivity disorder. J Addict Dis 2002;21:1-16. [PubMed: 11916368]

Levin FR, Evans SM, Brooks DJ, Kalbag AS, Garawi F, Nunes EV. Treatment of methadonemaintained patients with adult ADHD: double-blind comparison of methylphenidate, bupropion and placebo. Drug Alcohol Depen 2006;81:137-48.

Mansari EI, Ghanbari R, Janssen S, Blier P. Sustained administration of bupropion alters the neuronal activity of serotonin, norepinephrine but not dopamine neurons in the rat brain. Neuropharmacology. 2008 [Epub ahead of print].

Miller M, Parker B, Keely J, Johnson J, Schall D. Searching for evidence of transfer between drug facilitators. Learning and Motivation 2002;33:197-229.

Miller, RR.; Oberling, P. Analogies between occasion setting and Pavlovian conditioning. In: Schmajuk, NA.; Holland, PC., editors. Occasion Setting: Associative Learning and Cognition in Animals. American Psychological Association; Washington, DC: 1998. p. 3-35. 
Munzar P, Goldberg SR. Dopaminergic involvement in the discriminative-stimulus effects of methamphetamine in rats. Psychopharmacology 2000;148:209-216. [PubMed: 10663437]

Murray JE, Bevins RA. The interoceptive Pavlovian stimulus effects of caffeine. Pharmacol Biochem Behav 2007a;86:838-846. [PubMed: 17477964]

Murray JE, Bevins RA. Behavioral and neuropharmacological characterization of nicotine as a conditional stimulus. Eur J Pharmacol 2007b;561:91-104. [PubMed: 17343849]

Newton TF, Roache JD, De La Garza R 2nd, Fong T, Wallace CL, Li SH, Elkashef A, Chiang N, Kahn R. Bupropion reduces methamphetamine-induced subjective effects and cue-induced craving. Neuropsychopharmacology 2006;31:1537-44. [PubMed: 16319910]

Newton TF, Roache JD, De La Garza R 2nd, Fong T, Wallace CL, Li SH, Elkashef A, Chiang N, Kahn R. Safety of intravenous methamphetamine administration during treatment with bupropion. Psychopharmacology 2005;182:426-35. [PubMed: 16163531]

Nisell M, Marcus M, Nomikos GG, Svensson TH. Differential effects of acute and chronic nicotine on dopamine output in the core and shell of the rat nucleus accumbens. Journal of Neural Transmission 1997;104:1-10. [PubMed: 9085189]

Nomikos GC, Damsma G, Wenkstern D, Fibiger HC. Effect of chronic bupropion on interstitial concentrations of dopamine in rat nucleus accumbens and striatum. Neuropsychopharmacology 1992;7:7-14. [PubMed: 1381923]

O'Brien CP. Anticraving medications for relapse prevention: a possible new class of psychoactive medications. The American Journal of Psychiatry 2005;162:1423-1431. [PubMed: 16055763]

O’Brien CP, Childress AR, Mclellan TA, Ehrman R. Classical conditioning in drug dependent humans. Annals of New York Academy of Sciences 1992;654:400-415.

Ortmann R. The conditioned place preference paradigm in rats: Effect of bupropion. Life Sciences 1985;37:2021-2027. [PubMed: 3934485]

Palmatier MI, Bevins RA. Facilitation by drug states does not depend on acquired excitatory strength. Behav Brain Research 2007;176:292-301.

Palmatier MI, Wilkinson JL, Metschke DM, Bevins RA. Stimulus properties of nicotine, amphetamine, and chlordiazepoxide as positive features in a pavlovian appetitive discrimination task in rats. Neuropsychopharmacology 2005;30:731-741. [PubMed: 15592350]

Palmatier MI, Peterson JL, Wilkinson JL, Bevins RA. Nicotine serves as a feature-positive modulator of Pavlovian appetitive conditioning in rats. Behav Pharmacol 2004;15:183-94. [PubMed: 15187576]

Parker B, Schaal D, Miller M. Drug discrimination using Pavlovian conditional discrimination paradigm in pigeons. Pharmacol Biochem Behav 1994;49:955-960. [PubMed: 7886113]

Quinton MS, Gerak LR, Moerschbaecher JM, Winsauer PJ. Effects of pregnanolone in rats discriminating cocaine. Pharmacol Biochem Behav 2006;85:385-92. [PubMed: 17055039]

Reichel CM, Linkugel JD, Bevins RA. Bupropion differentially impacts acquisition of methamphetamine self-administration and sucrose-maintained behavior. Pharmacol Biochem Behav 2008;89:463-72. [PubMed: 18329085]

Reichel CM, Wilkinson JL, Bevins RA. Methamphetamine functions as a positive and negative drug feature in a Pavlovian appetitive discrimination task with rats. Behav Pharmacol 2007a;18:755765. [PubMed: 17989513]

Reichel CM, Linkugel JD, Bevins RA. Nicotine as a conditioned stimulus: impact of attention-deficit/ hyperactivity disorder medications. Exp Clin Pharmacol 2007b;15:501-509.

Rauhut AS, Neugebauer N, Dwoskin LP, Bardo MT. Effect of bupropion on nicotine selfadministration in rats. Psychopharmacology 2003;169:1-9. [PubMed: 12811464]

Sasaki JE, Tatham TA, Barrett JE. The discriminative stimulus effects of methamphetamine in pigeons. Psychopharmacology 1995;120:303-10. [PubMed: 8524978]

Siegel S, Ramos BM. Applying laboratory research: drug anticipation and the treatment of drug addiction. Experimental and Clinical Psychopharmacology 2002;10:162-183. [PubMed: 12233979]

Shoaib M, Sidhpura N, Shafait S. Investigating the actions of bupropion on dependence-related effects of nicotine in rats. Psychopharmacology 2003;165:405-412. [PubMed: 12451438] 
Spealman RD, Madras BK, Bergman J. Effects of cocaine and related drugs in nonhuman primates. II. Stimulant effects on schedule-controlled behavior. J Pharmacol Exp Ther 1989;251:142-149. [PubMed: 2795456]

Tella SE, Ladenheim B, Cadet JL. Differential Regulation of dopamine transporter after chronic selfadministration of bupropion and nomifensine. J Pharmacol Exp Ther 1997;281:508-513. [PubMed: 9103538]

Terry P, Katz JL. Dopaminergic mediation of the discriminative stimulus effects of bupropion in rats. Psychopharmacology 1997;134:201-212. [PubMed: 9399385]

Troisi J, Akins C. The discriminative stimulus effects of cocaine in a Pavlovian sexual approach paradigm in male Japanese quail. Exp Clin Psychopharmacol 2004;12:237-242. [PubMed: 15571440]

Wilkinson JL, Palmatier MI, Bevins RA. Preexposure to nicotine alters the subsequent locomotor stimulant effects of bupropion in rats. Nicotine Tob Res 2006;8:141-146. [PubMed: 16497608]

Wilkinson JL, Bevins RB. Bupropion hydrochloride produces conditioned hyperactivity in rats. Physiology \& Behavior 2007;90:790-796. [PubMed: 17300819]

Wiley JL, Lavecchia KL, Martin BR, Damaj MI. Nicotine-like discriminative stimulus effects of bupropion in rats. Exp Clin Psychopharm 2002;10:129-35.

Young R, Glennon RA. Nicotine and bupropion share a similar discriminative stimulus effect. Euro J Pharmacol 2002;443:113-8. 
A

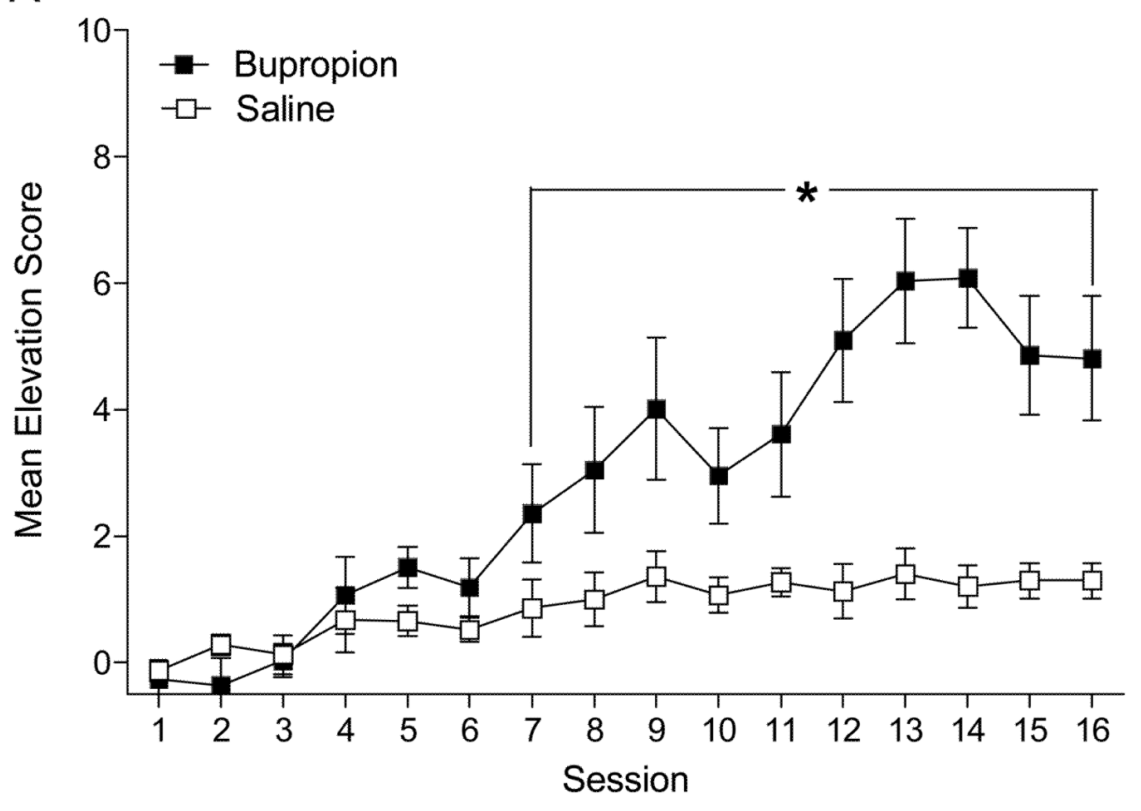

B

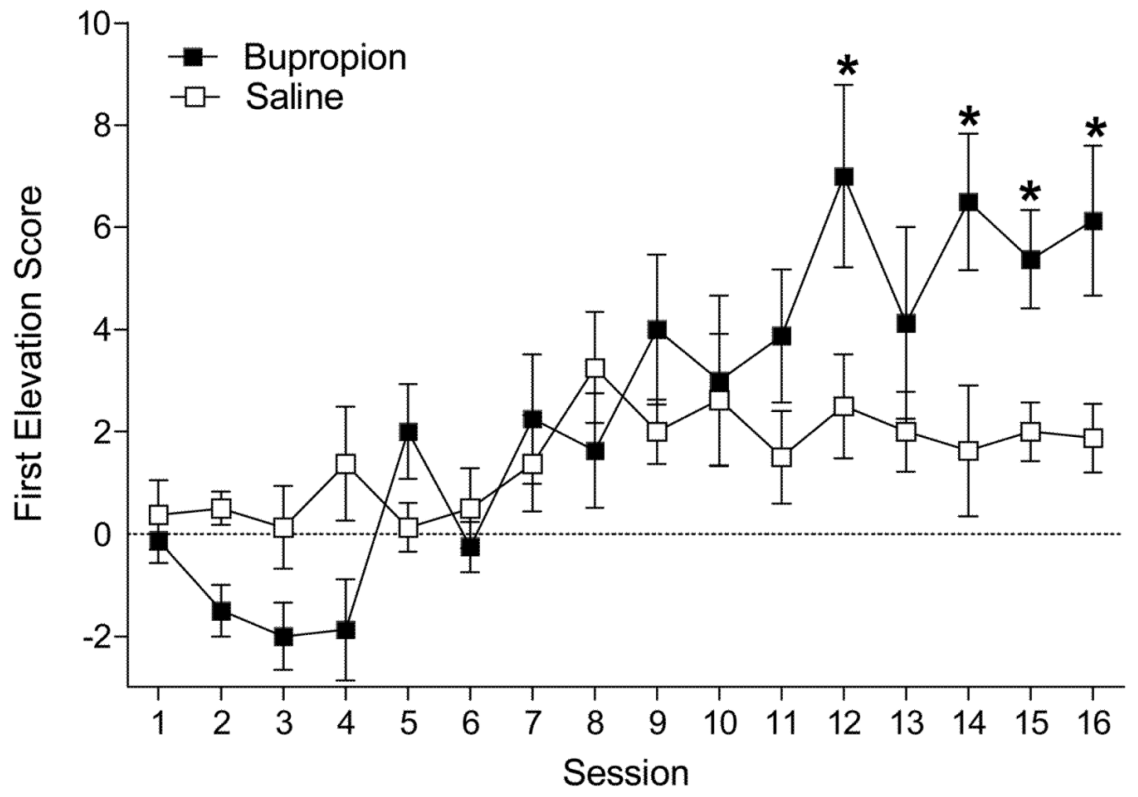

Figure 1.

Mean session (A) and first (B) elevation scores ( \pm 1 SEM) are shown for the acquisition phase. * denotes significant difference from corresponding saline elevation score. 


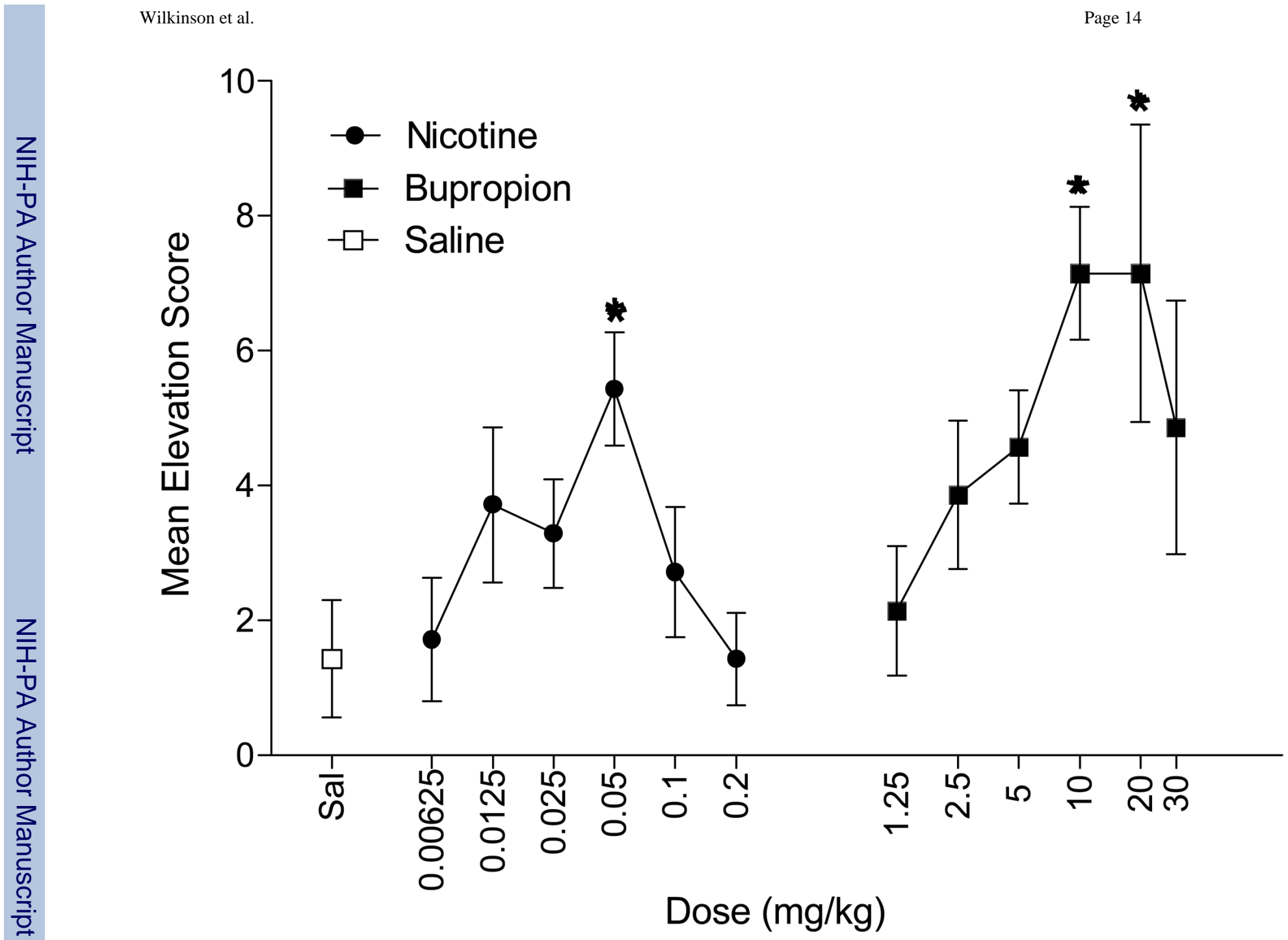

Figure 2.

Mean elevation scores ( \pm 1 SEM) during bupropion and nicotine substitution test phase are shown. * denotes significant difference from saline elevation score. 
A

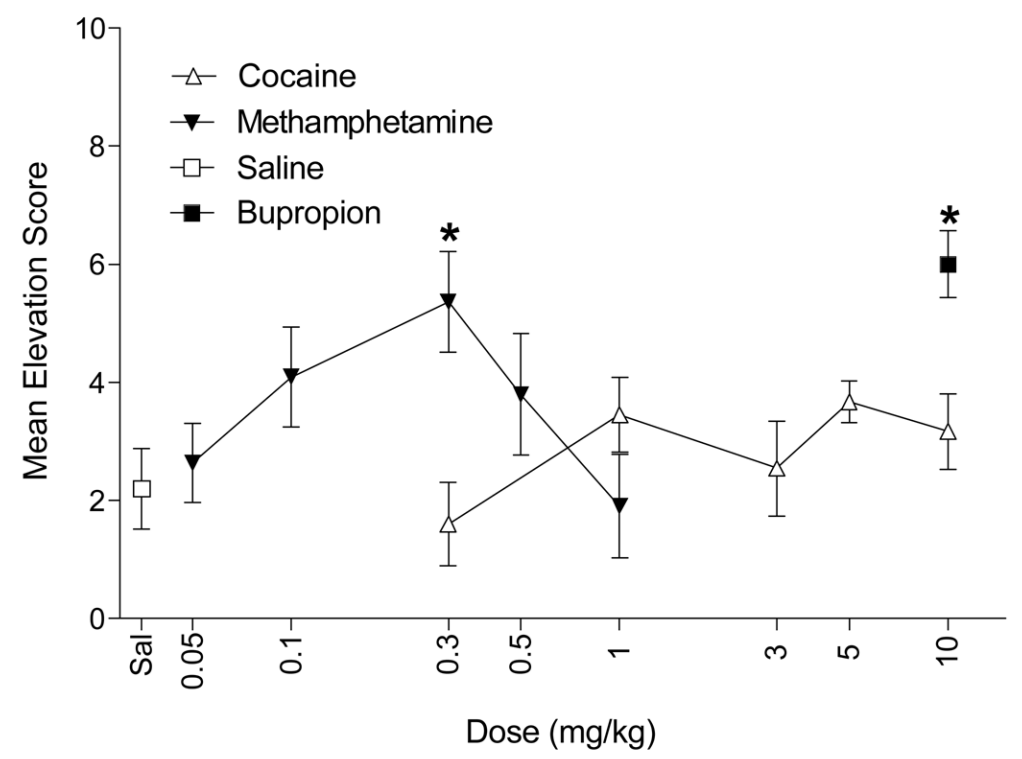

B

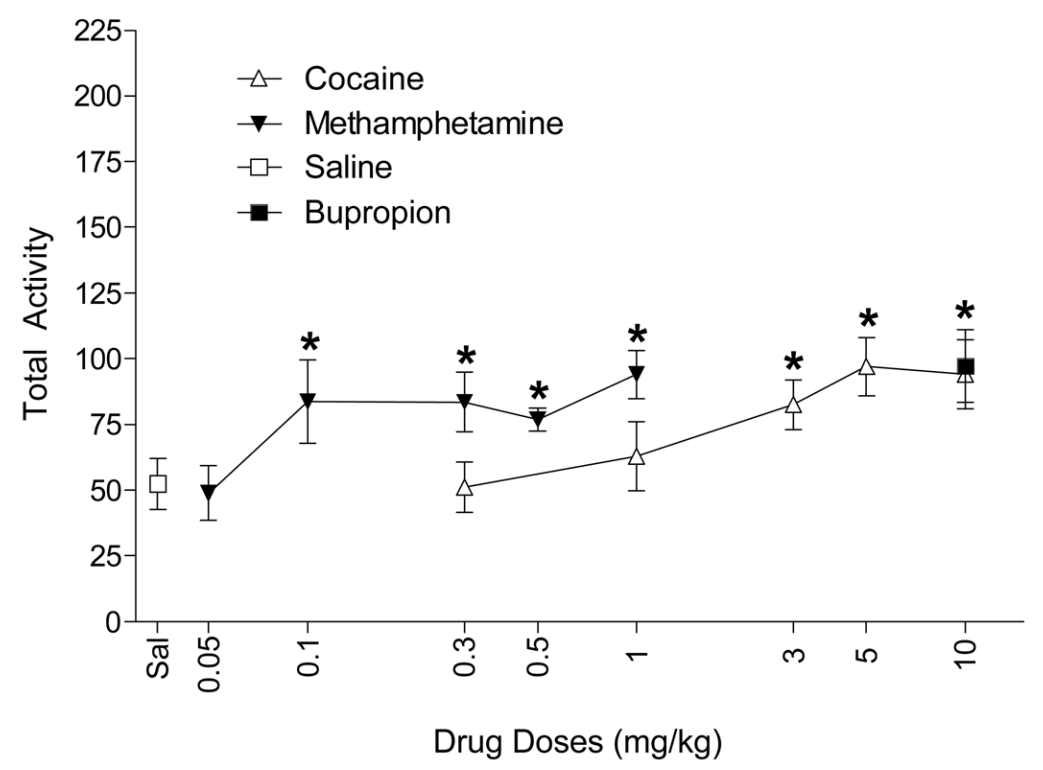

Figure 3.

Mean elevation (A) and general activity (B) scores ( \pm 1 SEM) during the cocaine and methamphetamine substitution phase are shown. * denotes significant difference from corresponding saline score. 